\title{
Morphological evaluation of variously intercalated pre-baked clay
}

\author{
Hameed Ullah*, Ahmad Imtiaz \\ University of Peshawar, Institute of Chemical Sciences, KPK, Pakistan \\ "Corresponding authors: e-mail: Hameed Ullah, hameedchemist@yahoo.com
}

\begin{abstract}
The use of porous materials is enjoying tremendous popularity and attention of the advance scientific communities due to their excellent adsorptive and catalytic activities. Clays are one of the most important candidates in the porous community which shows the above mentioned activities after modifing with a different intercalating agent. The paper is focused on the influence of some inorganic intercalating agents $(\mathrm{NaOH})$ on the morphology of the variously intercalated clay samples. The alkali metal was used as the inorganic intercalating agent. The effect of intercalation temperature, intercalation agent concentration and intercalation time on the pre-baked clay morphology were also part of the study. Scanning electron microscopy (SEM) study was performed to evaluate the morphological changes of the resultant intercalates. Different morphological properties were improved significantly in the case of the inorganically modified clay samples. Thus, such intercalations are suggested to be effective if the clays under study are to be used for different industrial process at elevated conditions.
\end{abstract}

Keywords: clay, alkali metal intercalation, inorganic modifier, scanning electron microscopy.

\section{INTRODUCTION}

Many of important and widely used materials are porous in their structure that's why the use of porous materials are enjoying tremendous popularity and attention of the advance scientific communities due to their excellent adsorptive and catalytic activities ${ }^{1-6}$. Clayey materials are one of the most important candidates in the porous community which shows the above mention properties $^{7-9}$. However, the use of these porous materials at elevated temperature and pressure cause blinding of the porous structure which adversely affect the catalytic and adsorptive properties ${ }^{10,11}$.

In order to overcome pore clogging and blinding problems of the porous structure, activation procedures have been adopted by the researcher to improve the materials surface and catalytic properties. Usman et al. used acids activation of porous clay to evaluate the bleaching ability of the activated clay ${ }^{\mathbf{1 2}}$. The activation of kaolinite clay to improve its adsorptive as well as catalytic properties was performed by panda et al. ${ }^{13}$. Physical treatment also used by number of researcher which involves calcination of clays at high temperatures ${ }^{14}$. Chaisena et al. also used thermal treatment for the activation of porous clay ${ }^{15}$. Some researchers use electrochemical methods for the activation of porous materials. Some clays have been activated by chemical and thermal treatment methods to obtain the chemically inert, fire-resistant, low-density materials with excellent thermal and acoustic insulation properties. Some researchers used acid and alkali treatment for surface properties modification of the selected minerals as reported earlier ${ }^{\mathbf{1 0}, 11}$.

However, to evaluate which methods of activation show excellent results, an ellaborative characterization of these porous materials regarding their pore size, surface area, porosity and pore size distribution, morphology and thermal properties are required to select and optimize the performance of porous and hierarchically structured $\&$ ordered materials for both direct and indirect use in many industrial applications ${ }^{16-19}$.

In this work we will study and evaluate the effectiveness of the intercalation procedure for original as well as variously intercalated pre-baked clay samples in turn of their morphological characteristic. Scanning Electron Microscopy and electron dispersive energy scattering (EDS) will be used for the characterization of the resulting materials.

\section{EXPERIMENTAL}

\section{Collection of sample}

Local available pre-baked clay sample was collected from brick kiln according to the standard procedure of sample collection, grounded, and dried in an oven at $105^{\circ} \mathrm{C}$ to make it free of surface moisture and were kept in control condition for onward use. The clay understudy was analyzed by scanning electron microscopy(SEM) and electron dispersive energy scattering (EDS) technique.

\section{Chemical activation}

Aqueous solutions of sodium hydroxide $(\mathrm{NaOH})$ were prepared in desired percentages, ie. 1, 5 and $10 \%$. Baked clay samples were intercalated in a vat with $\mathrm{NaOH}$ separately while varying experimental conditions like temperature, mixing ratio of intercalating agents and holding time of intercalation.

\section{Effect of temperature}

To study the effect of reaction temperature on surface morphology of clay understudy, $1 \mathrm{~g}$ portions of baked clay sample were subjected separately to solvent intercalation using aqueous solutions of $\mathrm{NaOH} .10 \mathrm{ml}$ aliquot of the respective solution was added to each sample and heated at different temperatures of 150, 500 and $750^{\circ} \mathrm{C}$, respectively. Each of the hydro thermally treated samples was washed with copious amount of de-ionized water to remove the unreacted sodium hydroxide, dried in a vacuum oven at $70^{\circ} \mathrm{C}$ in order to remove all the surface and entrapped moisture. The prepared samples were kept in vials for SEM and EDX study. 


\section{Effect of mixing ratio}

In order to evaluate the effect of the mixing ratio on surface morphology of the clay understudy, $1 \mathrm{~g}$ of sample was intercalated using $\mathrm{NaOH}$ prepared in different concentration of 1,5 and $10 \%$, separately. Further, treatment was done in a similar manner as given above.

\section{Effect of holding time}

To study the holding time influence, $1 \mathrm{~g}$ of baked clay sample was intercalated for the time duration of $5 \mathrm{~h}, 15 \mathrm{~h}$ and $24 \mathrm{~h}$, separately. Each of the treated samples was washed with deionized water till free of $\mathrm{NaOH}$, dried in an oven and used for further analysis.

\section{SEM Analysis}

Original and variously modified clay samples micrographs were obtained by Scanning Electron Microscope (SEM) Model JSM 5910 JEOL Company Japan. Both original and modified clay samples were mounted on a gold coated disc.

\section{EDX Analysis}

Energy dispersive X-ray spectrophotometer (EDX) Model Inea 200, Made UK, Company Oxford was conducted for the analysis of original and intercalated clay samples.

\section{RESULTS AND DISCUSSION}

The scanning electron microscopic (SEM) technique is unique to study clays morphology as it affords a magnified, three-dimensional view of the unmodified (original) and variously intercalated clay surfaces with great depth of focus. Energy dispersive X-ray spectrophotometer (EDX) is also a relatively easy, simple yet powerful technique for the study of the elemental composition of as little as a cubic micron of the sample.

The SEM micrograph of the original clay understudy is provided in Figure 1. The micrograph shows the typical

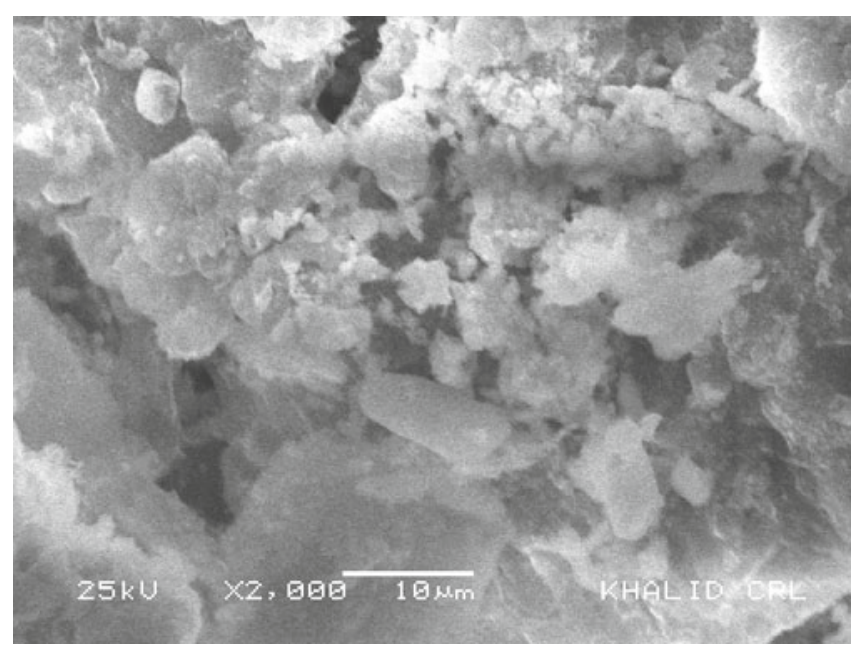

Figure 1. SEM micrograph of the original Clay sample

surface of the porous clay. The micrograph in the Figure confirmed the presence of interstratified clay. SEM micrograph also indicates that some prominent minerals like quartz, kaolinite, micas, vermiculite, calcite and feldspars are present in the clay samples understudy. The EDX signature of the original clay sample shows the presence of alumina, silica and iron as major clay constituents. EDX spectrum also indicating the presence of potassium, calcium and titanium as minor constituents of the clay understudy. EDX of the original pre-baked clay sample also shows some traces of sulfur which attributed to the presence of some sulfur containing organic compounds as the pre-baked clay samples were collected from the brick kiln industries where the labor used some tires and other organic structures for brick cooking in the brick kiln industry.

\section{Effect of temperature on clay morphology}

The effect of the intercalation temperature was also part of the study which helps in evaluating the morphological changes of the pre baked clay samples subjecting to different intercalation temperature (ambient, 150, 500

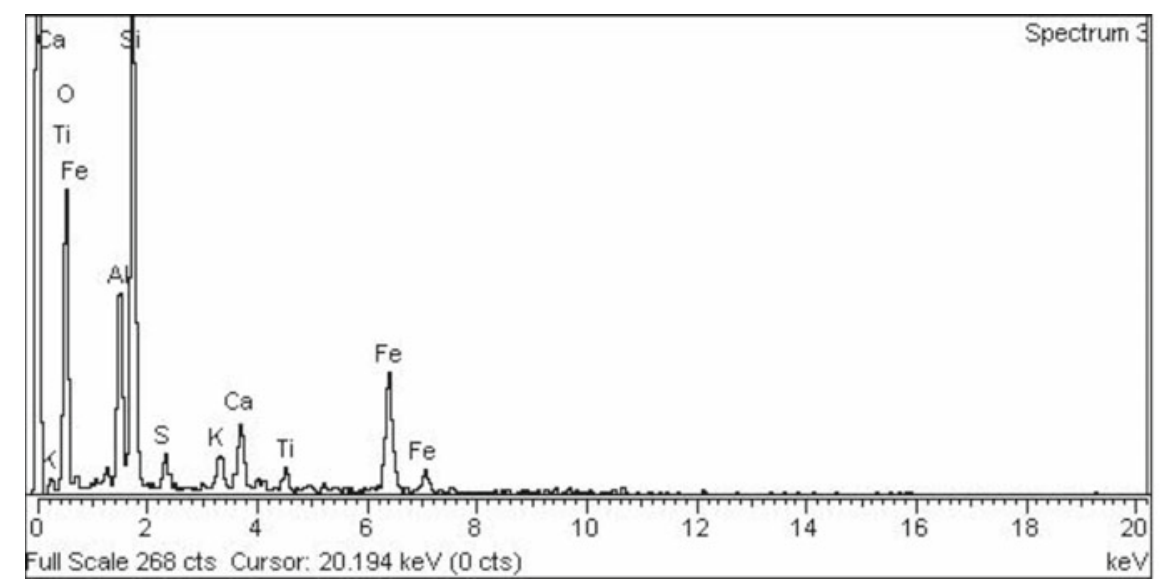

\begin{tabular}{|l|r|r|}
\hline Element & Weight, \% & Atomic, \% \\
\hline O K & 43.94 & 63.33 \\
Al K & 8.28 & 7.08 \\
Si K & 20.20 & 16.58 \\
S K & 1.61 & 1.16 \\
K K & 2.08 & 1.23 \\
Ca K & 3.85 & 2.21 \\
Ti K & 1.97 & 0.95 \\
Fe K & 18.07 & 7.46 \\
\hline Totals & 100.00 & \\
\hline
\end{tabular}

Figure 2. EDX signature of the original Clay sample

Table 1. Elemental composition of the clay sample treated with $\mathrm{NaOH}$ at different temperature (a) ambient, (b) $150^{\circ} \mathrm{C},(\mathrm{c}) 500^{\circ} \mathrm{C}$, (d) $750^{\circ} \mathrm{C}$

\begin{tabular}{|l|c|c|c|c|c|c|c|c|c|}
\hline Condition & $\mathrm{O}$ & $\mathrm{Al}$ & $\mathrm{Si}$ & $\mathrm{S}$ & $\mathrm{K}$ & $\mathrm{Ca}$ & $\mathrm{Ti}$ & $\mathrm{Fe}$ & $\mathrm{Na}$ \\
\hline Original & 44 & 8.0 & 20 & 1.6 & 2.0 & 3.8 & 2.0 & 18.0 & - \\
\hline $25^{\circ} \mathrm{C}$ & 35 & 6.4 & 15 & - & 1.3 & 6.0 & 1.5 & 17.0 & - \\
\hline $150^{\circ} \mathrm{C}$ & 44 & 8 & 16 & - & 1.8 & 4.3 & 1.8 & 14.1 & 10.3 \\
\hline $500^{\circ} \mathrm{C}$ & 47 & 9.1 & 15 & - & 2.2 & 5.5 & - & 10.6 & 12.2 \\
\hline $750^{\circ} \mathrm{C}$ & 35 & 2.0 & 7.0 & - & 0.8 & 4.0 & - & 4.6 & 12.2 \\
\hline
\end{tabular}



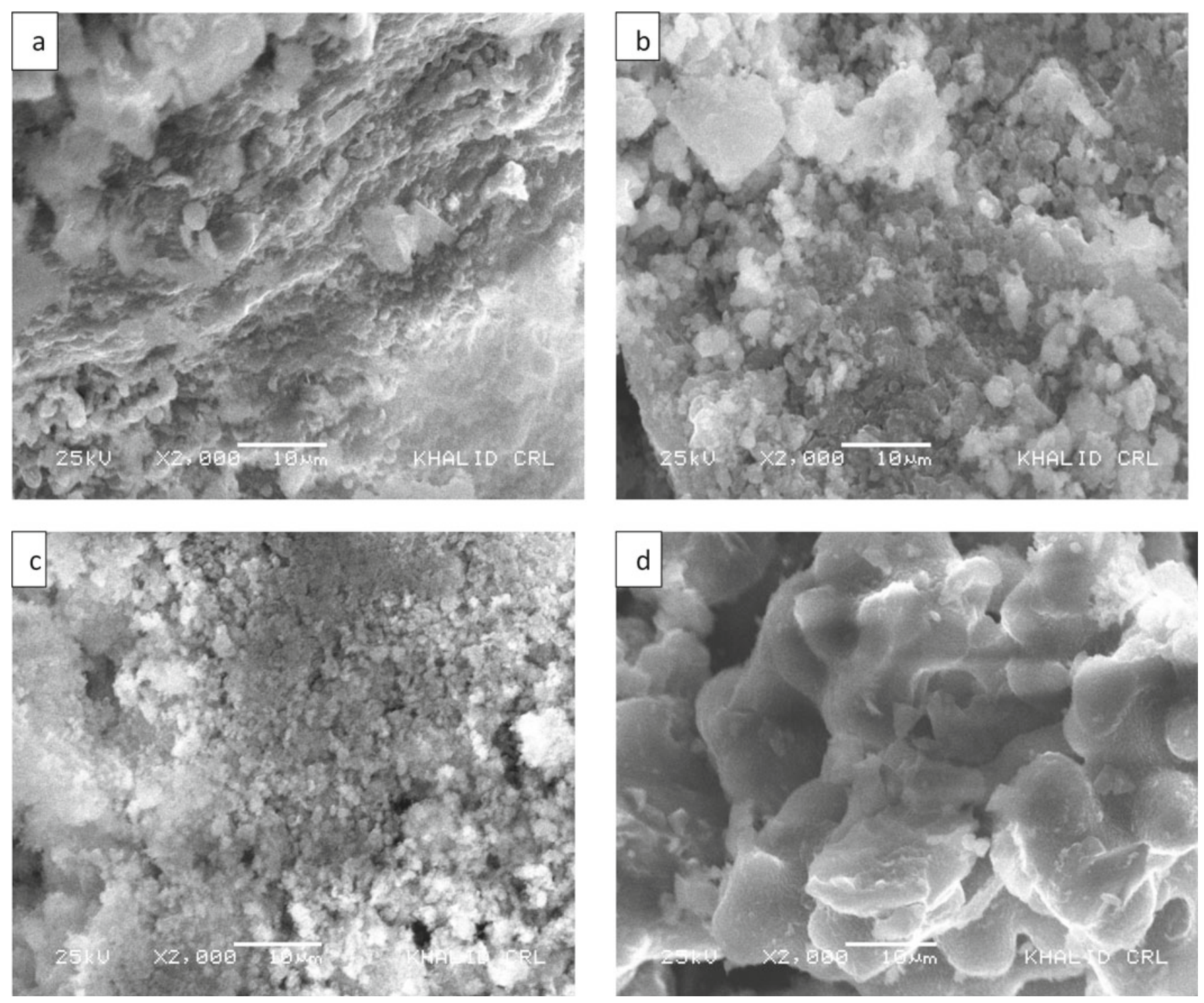

Figure 3. SEM micrograph of sample treated with $\mathrm{NaOH}$ at different temperatures (a) Ambient, (b) $150^{\circ} \mathrm{C}$, (c) $500^{\circ} \mathrm{C},(\mathrm{d}) 750^{\circ} \mathrm{C}$
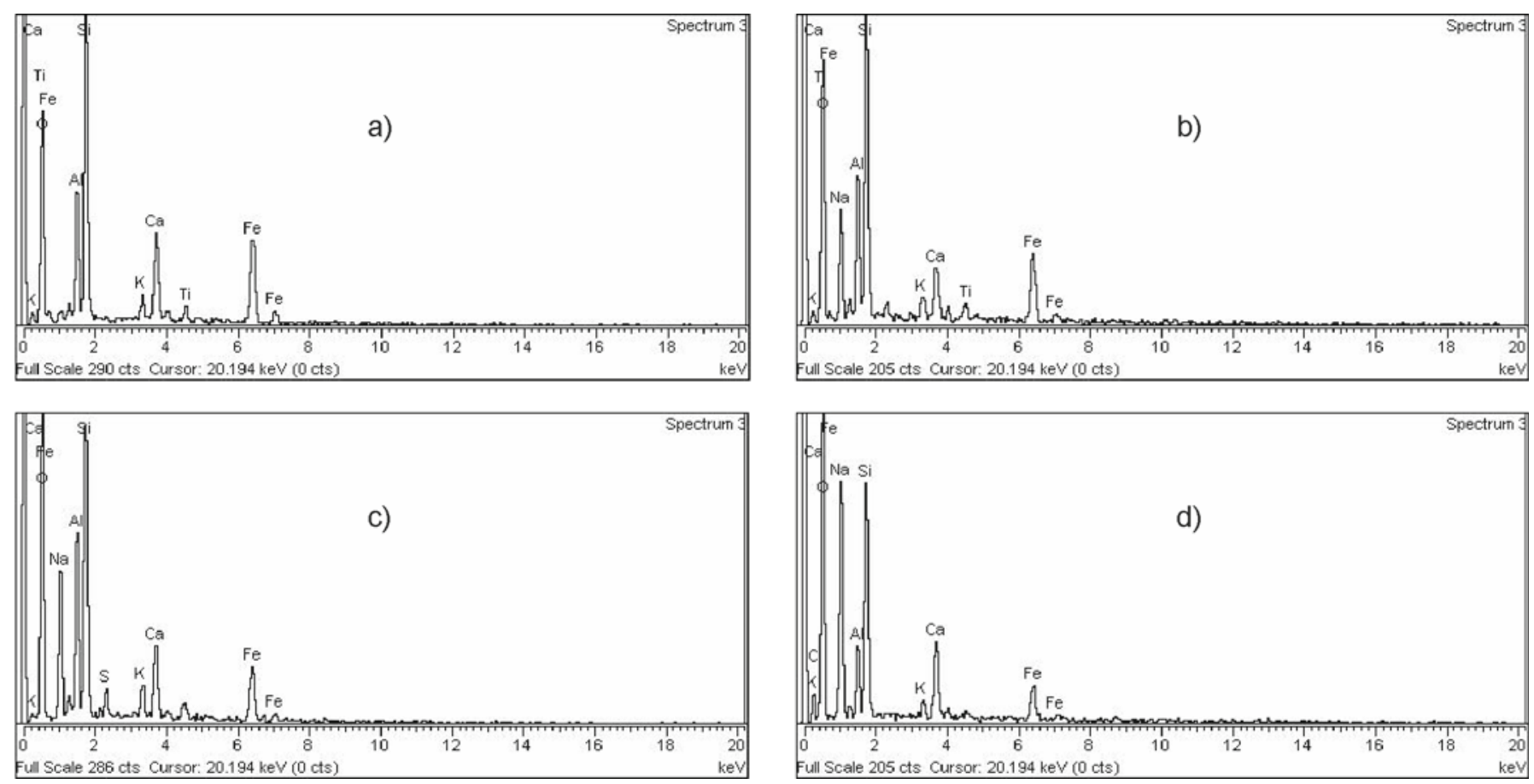

Figure 4. EDX signatures of sample treated with $\mathrm{NaOH}$ at different temperature (a) ambient, (b) $150^{\circ} \mathrm{C},(\mathrm{c}) 500^{\circ} \mathrm{C},(\mathrm{d}) 750^{\circ} \mathrm{C}$ 
and $750^{\circ} \mathrm{C}$ ). The SEM micrographs of pre baked clay samples under different intercalation temperature were given in Figure 3. It is evident from the micrograph that intercalation temperature has changed the clay morphology after subjecting the clay samples to different intercalation temperatures. Intercalation at ambient temperature doesn't show any measureable changes in the intercalated clay sample. However, at mild temperature conditions the surface morphology shows little variation as the clay surface starts conversion to some particle form. Subjecting the clay sample to higher intercalation temperature i.e $500^{\circ} \mathrm{C}$, decrease was observed in the particle size of the intercalated sample. However, at elevated temperature the smaller particles of the prebaked clay sample coalesce into a bigger particles form.

The EDX signatures of the clay samples intercalated at different temperatures are also given in Figure 4 while the elemental data is provided in Table 1. From the data in the table it is confirmed that there is an increase in alumina content of the clay samples subjected to temperature up to $500^{\circ} \mathrm{C}$. However, at elevated temperature i.e $750^{\circ} \mathrm{C}$, the alumina content abruptly decreases to $2 \%$. The effect of temperature on the alumina content has been studied elsewhere where the alumina content of the clay understudy was decreasing with increasing the temperature ${ }^{20}$. This decrease in alumina content is due to the dissolution rate of alumina which was high when the temperature is increased The silica contents of the clay sample is also decreasing in the linear order when the clay sample subjected to higher temperature.

Another very interesting behavior which is confirmed from the EDX elemental data is the decrease in the iron content of the clay samples. The iron content of the original prebaked clay sample was $18 \%$ which upon subjecting to intercalation temperature decreases to $17 \%$ at ambient intercalation temperature. The iron content further decreases to $14 \%$ at $150^{\circ} \mathrm{C}$ intercalation temperature and to $10 \%$ when the intercalation temperature was $500^{\circ} \mathrm{C}$. The iron content shows very meaningfull decrease which is $4 \%$ after intercalation at elevated intercalation temperature $\left(750^{\circ} \mathrm{C}\right)$.

\section{Effect of intercalating agent concentrations on clay morphology}

In the project we have also studied the effect of intercalating agent concentrations on the morphological
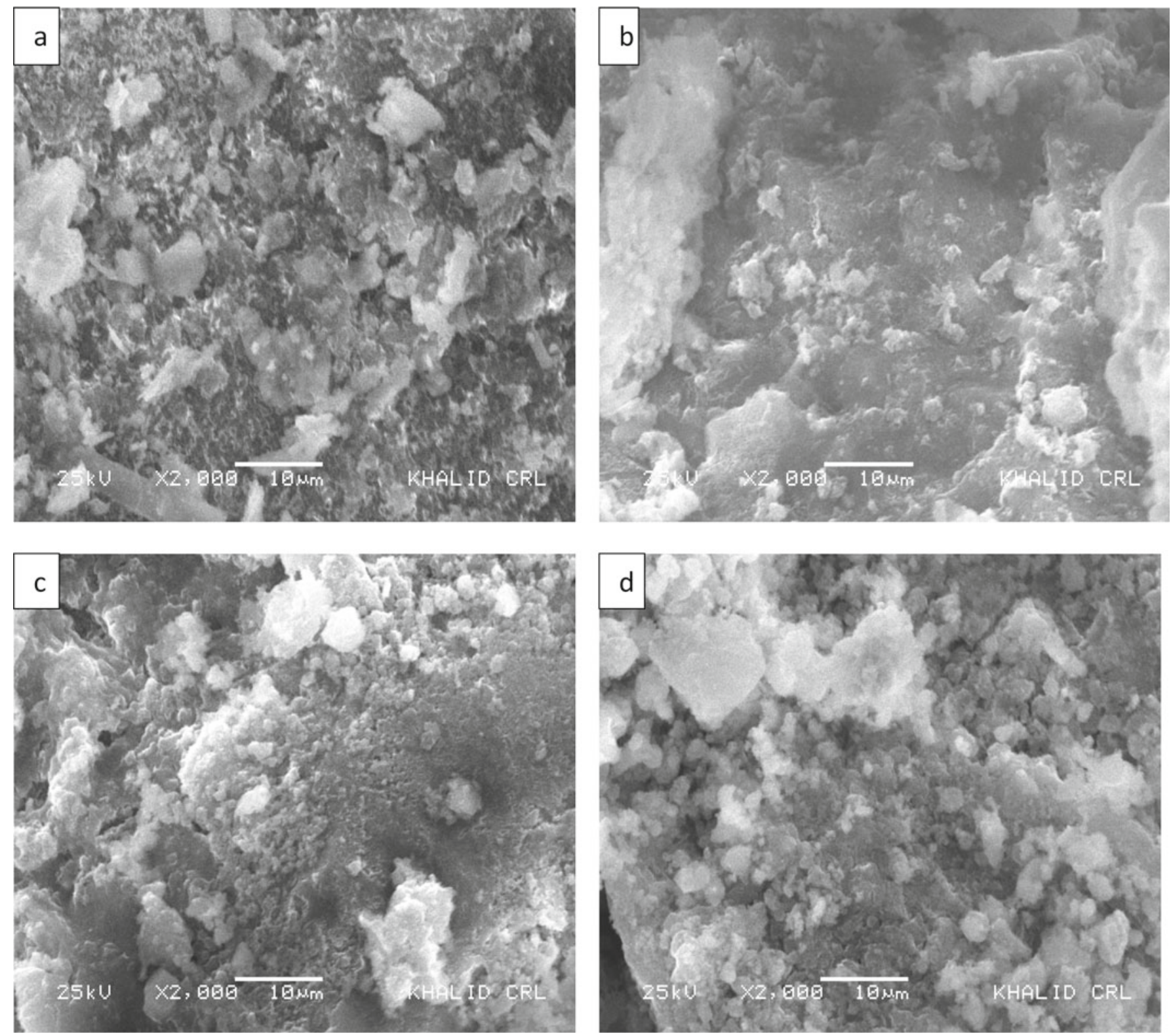

Figure 5. SEM micrograph of sample treated with different concentration of $\mathrm{NaOH}$ (a) $0 \%$, (b) $1 \%$, (c) $5 \%$, (d) $10 \%$ 

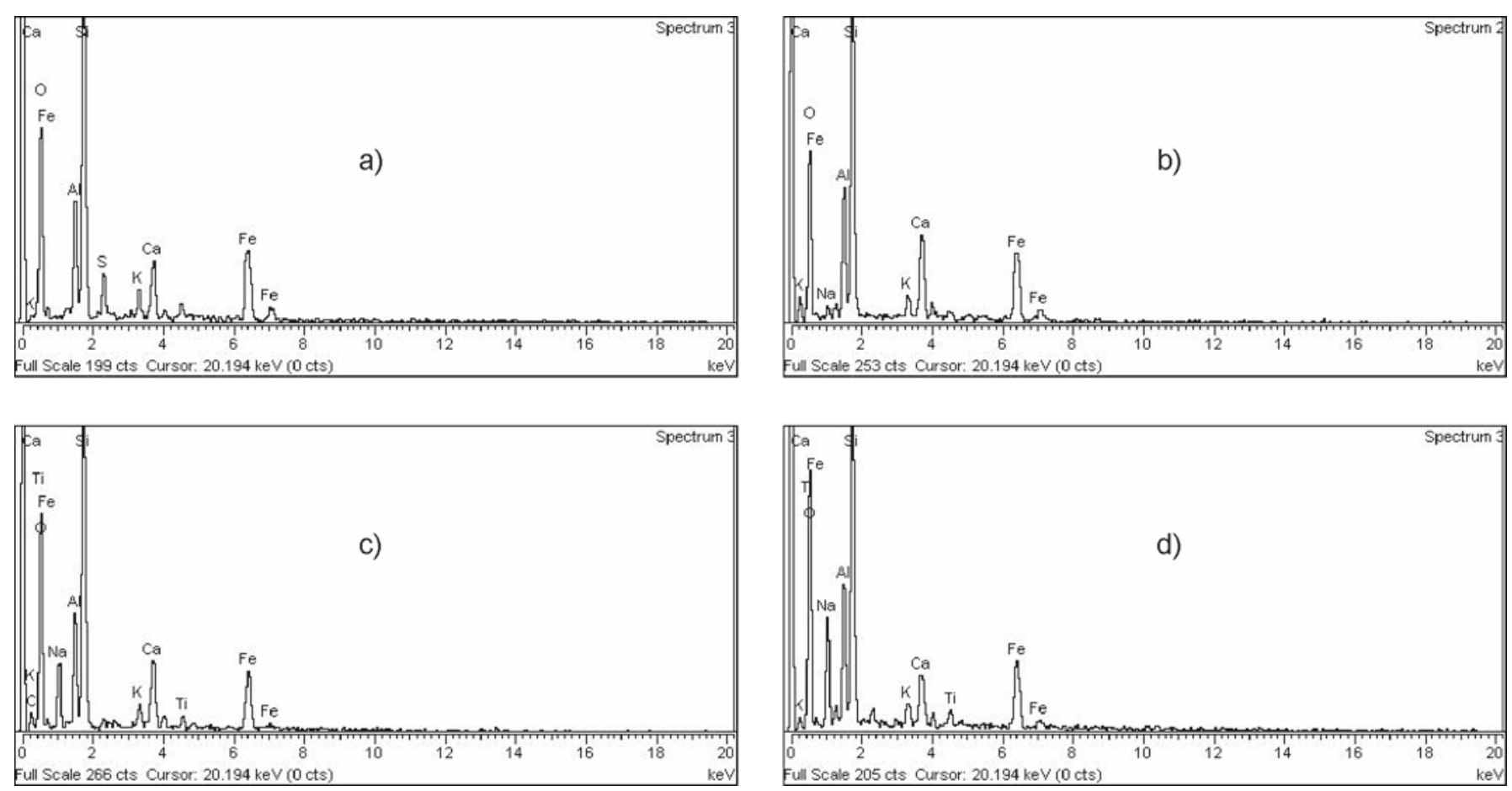

Figure 6. EDX signatures of sample treated with different concentration of $\mathrm{NaOH}$ (a) $0 \%$, (b) $1 \%$, (c) $5 \%$, (d) $10 \%$

Table 2. Elemental composition of the clay sample intercalated with different concentration of $\mathrm{NaOH}$ (a) $0 \%$, (b) $1 \%$, (c) $5 \%$, (d) $10 \%$

\begin{tabular}{|l|c|c|c|c|c|c|c|c|c|}
\hline Condition & $\mathrm{O}$ & $\mathrm{Al}$ & $\mathrm{Si}$ & $\mathrm{S}$ & $\mathrm{K}$ & $\mathrm{Ca}$ & $\mathrm{Ti}$ & $\mathrm{Fe}$ & $\mathrm{Na}$ \\
\hline Original & 44 & 8.0 & 20 & 1.6 & 2.0 & 3.8 & 2.0 & 18.0 & - \\
\hline $0 \%$ & 22 & 4.0 & 10.2 & 1.9 & 1.1 & 2.7 & - & 10.0 & - \\
\hline $1 \%$ & 34 & 6 & 12 & - & 1.3 & 6.3 & - & 13.0 & 2.0 \\
\hline $5 \%$ & 33 & 5 & 13 & - & 1.2 & 4.8 & 1.0 & 9.22 & 5.2 \\
\hline $10 \%$ & 44 & 7 & 16 & - & 1.7 & 4.0 & 1.7 & 14.0 & 10.2 \\
\hline
\end{tabular}

Table 3. Elemental composition of the clay sample treated with $\mathrm{NaOH}$ at different intercalation time (a) $0 \mathrm{hr}$, (b) $5 \mathrm{hr}$, (c) $15 \mathrm{hr}$, (d) $24 \mathrm{hr}$

\begin{tabular}{|l|c|c|c|c|c|c|c|c|c|}
\hline Condition & $\mathrm{O}$ & $\mathrm{Al}$ & $\mathrm{Si}$ & $\mathrm{S}$ & $\mathrm{K}$ & $\mathrm{Ca}$ & $\mathrm{Ti}$ & $\mathrm{Fe}$ & $\mathrm{Na}$ \\
\hline Original & 44 & 8.0 & 20 & 1.6 & 2.0 & 3.8 & 2.0 & 18.0 & - \\
\hline $0 \mathrm{hr}$ & 44 & 8.0 & 20 & 1.6 & 2.0 & 3.8 & 2.0 & 18.0 & - \\
\hline $5 \mathrm{hr}$ & 25 & 4 & 10 & - & 0.8 & 3.3 & - & 7.0 & 3.2 \\
\hline $15 \mathrm{hr}$ & 26 & 4.0 & 12.5 & - & - & 3.6 & - & 6.5 & 4.0 \\
\hline 24 & 44 & 7.4 & 16 & - & 1.8 & 4.2 & 1.8 & 14.0 & 10 \\
\hline
\end{tabular}

features of clay samples. The SEM micrographs of the clay samples intercalated with different concentration of intercalating agents are provided in Figure 5. It is evident from the SEM photograph that intercalation of the clay at different intercalating agent concentrations has marked effect on the clay morphology. After intercalation of the clay matrix, luminous as well as non-luminous features could be seen. The bright luminosity was due to the presence of aluminum or sodium. As we are increasing the intercalating agent $(\mathrm{NaOH})$, the clay sample shows higher bright luminosity as the sodium content of the clay sample increasing. The same is also confirmed by the EDX signature as the sodium content of clay sample intercalated with different sodium concentration. The sodium content of the intercalated clay sample was $2 \%$ in the case of $1 \% \mathrm{NaOH}$ solution intercalation, where in the case of $5 \%$ and $10 \%$ sodium hydroxide intercalation of clay, the sodium content was 5.2 and $10.2 \%$, respectively. As evidently seen from the micrograph in Figure 5, the intercalated clay surface was comparatively with much more rough and irregular surface structure when sodium hydroxide concentration was zero. However, when the concentration of the sodium hydroxide was increasing, the surface of the intercalated clays were becoming regular and ordered. The effect of the sodium hydroxide concentration on the pore and surface structure of the clay was also studied by other group of researchers ${ }^{21}$.

It is also inferred from the data in Table 2, with increase in the sodium content of the clay sample, the calcium content of the intercalated clay samples were showing a decreasing trend which might be due to the exchange of sodium of the intercalated solution with calcium content of the clay understudy. It is very often in porous clay materials where the calcium of the clay exchange with sodium content of the intercalation agents ${ }^{22}$.

\section{Effect of Intercalation time on clay morphology}

In this project we have also dug out the effect of intercalation time interval on the surface and pore morphology of the clay understudy. The scanning electron microscopic images of the clays intercalated with intercalating agent at different intercalation holding time were provided in Figure 7. with the corresponding EDX signatures in Figure 8. 

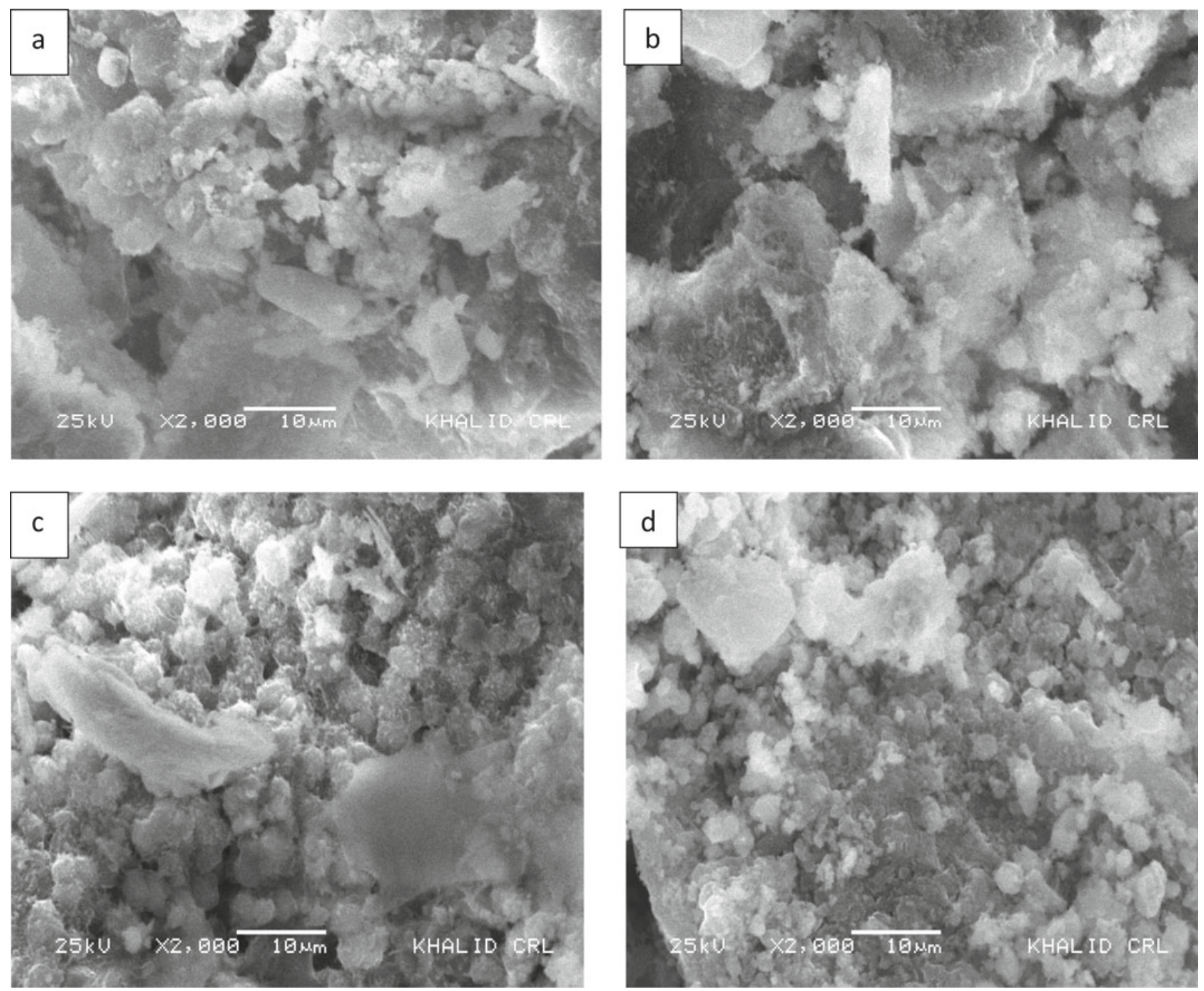

Figure 7. SEM micrographs of sample treated with $\mathrm{NaOH}$ for different intercalation time (a) 0 hr, (b) 5 hr, (c) 15 hr, (d) 24 hr
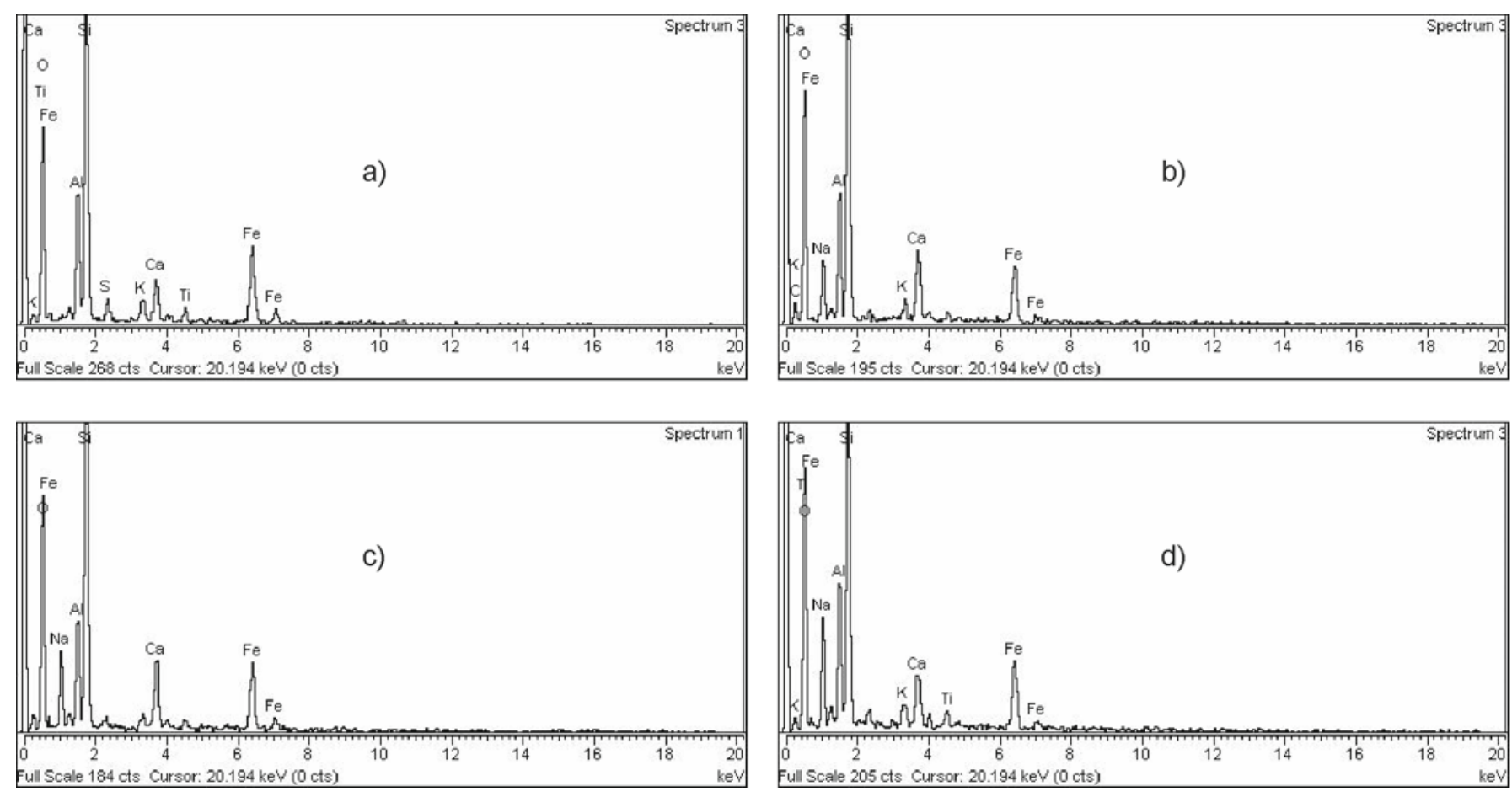

Figure 8. EDX signatures of sample treated with $\mathrm{NaOH}$ at different intercalation time (a) $0 \mathrm{hr}$, (b) $5 \mathrm{hr}$, (c) $15 \mathrm{hr}$, (d) $24 \mathrm{hr}$ 
It is clear from the SEM micrograph that intercalation holding time affect the clay morphology. The micrograph of the clay sample understudy at $0 \mathrm{hr}$ intercalation time shows some etched pits, layers, some islands and hills \& valleys which could be seen randomly distributed through the micrograph as provided in Figure 8 (a). The same can observed when the holding time increase to $5 \mathrm{hr}$. However, when the holding intercalation time was increased between clay understudy and intercalation agents $(\mathrm{NaOH})$, the clay structure morphology was changed meaningfully which shows the effect of intercalation time on clay morphology as confirmed by the SEM images provided in Figure 8 (c, d). The particles shape reveals that changed to the clay particle sizes as shown in Figure. At 15 and $24 \mathrm{hr}$, the clay particle modified with somewhat round shap where increase in luminicity was seen which is the clear example of sodium incorporation in the clay structure. The increase in sodium content has also been seen in the EDS signature provided in Figure 8. From the data given in Table 3, it is also established that sodium content of the clay upon intercalation at holding time of 15 and $24 \mathrm{hr}$ increase to $4 \%$ and $10 \%$ where the sodium content in the original clay samples was zero.

\section{CONCLUSIONS}

It is concluded from the study that alkali metal are a potential candidate for the activation of clay materials. Intercalation temperature shows a meaningful effect on the morphological characteristic of the clay. Activating agent concentration and intercalation time of the intercalation procedure also have some effects and must be properly controlled in order to obtain clay morphology of the desired properties.

\section{ACKNOWLEDGMENT}

The author is grateful to Higher Education Commission of Pakistan for financial support and Centralized Resources Laboratory, University of Peshawar for SEM and EDS analyses

\section{LITERATURE CITED}

1. Thomas, K.M. (2007). Hydrogen adsorption and storage on porous materials. Catal Today. 120, 389-398 01/2007; DOI: 10.1016/j.cattod.2006.09.015.

2. Zhao, D. \& Wang, Y. (2007). In: Introduction to Zeolite Science and Practice (Eds: J. Cejka, H. van Bekkum, A. Corma, F. Schüth), Stud. Surf. Sci. Catal. 168, Chapter 8, Elsevier, Amsterdam.

3. Kleitz, F. (2008). Handbook of Heterogeneus Catalysis (Eds: G. Ertl, H. Knoetzinger, F. Schueth, J. Weitkamp), Wiley-VCH Verlag GmbH \& Co KgaA, Weinheim.

4. Roth, W.J. \& Vartuli, J.C. (2005). Progress and Prospects, Stud Surf Sci Catal (Eds: J. Cejka, H. van Bekkum) 91.

5. Hartmann, M. (2005). Adsorption of vitamin E on mesoporous carbon molecular sieves. Chem. Mater. 17, 829-833. DOI: $10.1021 / \mathrm{cm} 048564 f$.

6. Hartmann, M. \& Jung, D. (2010). Biocatalysis with enzymes immobilized on mesoporous hosts: the status quo and future trends. J. Mater. Chem. 20, 844. DOI: 10.1039/B907869J.

7. Mumin, M.A., Khan, M.M.R., Akhter, K.F. \& Uddin, M.J. (2007). Potentiality of open burnt clay as an adsorbent for the removal of Congo red from aqueous solution. Int. J. Environ. Sci. Tech. 4 (4), 525-532.

8. Krishna, B.S., Murty, D.S.R. \& Jai Prakash, B.S. (2001). Surfactant-modified clay as adsorbent for chromate. Appl Clay Sci. 20 (1-2), 65-71. DOI.10.1016/S0169-1317(01)00039-4.

9. Karthikeyan, G., Pius, A. \& Alagumuthu, G. (2005). Fluoride adsorption studies of montmorillonite clay. Indian J. Chem. Techn. 12(3), 263-272.

10. Lang, F. \& Kaupenjohann, M. (2002). Immobilisation of molybdate by iron oxides: Effect of organic coatings. Geoderma. 1910, 1-16.

11. Kaiser, K. \& Guggenberger, G. (2003). Mineral surface and soil organic matter. Eur. J. Soil Sci. 54,1-18. DOI: 10.1046/ j.1365-2389.2003.00544.

12. Usman, M.A., Ekwueme, V.I., Alaje, T.O. \& Mohammed, A.O. (2012). Characterization, Acid Activation, and Bleaching Performance of Ibeshe Clay, Lagos, Nigeria. ISRN Ceramics. Article ID 658508, 5 pages, DOI: 10.5402/2012/658508.

13. Panda, A.K., Mishra, B.G., Mishra, D.K. \& Singh, R.K. (2010). Effect of sulphuric acid treatment on the physicochemicalcharacteristics of kaolin clay. Colloids Surf., A. 363, 98-104.

14. Asheh, S., Banat, F. \& Abu-Aitah, L. (2003). Sep. Pur. Tech., 33, 10.

15. Chaisena, A. \& Rangsriwatananon, K. (2004). Effects of thermal and acid treatments on some phisico-chemical properties of lampang diatomitr. J. Sci. Technol. 11, 289.

16. Sing, K.S.W., Everett, D.H., Haul, R.A.W., Mouscou, L., Pierotti, R.A., Rouquerol, J. \& Siemieniewska, T. (1985). Pure Appl. Chem. 57, 603. DOI:10.1351/pac198557040603.

17. Rouquerol, F., Rouquerol, J. \& Sing, K. (1999). Adsorption by Powders and Porous Solids, Academic Press, London.

18. Lowell, S., Shields, J., Thomas, M.A. \& Thommes, M. (2004). Characterization of Porous Solids and Powders: Surface Area, Pore Size and Density, Springer, The Netherlands.

19. Gregg, S.J. \& Sing, K.S.W. (1982). Adsorption, Surface Area and Porosity, Academic Press, London.

20. Ajemba, R.O. \& Onukwuli, O.D. (2012). Dissolution kinetics and mechanisms of reaction of Udi clay in nitric acid solution. AJSIR. DOI: 10.5251/ajsir.2012.3.3.115.121.

21. Tsai, WT., Hsien, K.J., \& Lai, C.W. (2004). Chemical Activation of Spent Diatomaceous Earth by Alkaline Etching in the Preparation of Mesoporous Adsorbents. Ind. Eng. Chem. Res. 43, 7513-7520.

22. Saidi, A., Shamanian, M., Barati, M. \& Azari, K. (2004). Hyperactivation of Bentonite in Pelletizing Process. International Journal of ISSI 1(1), 38-41. 